\title{
The Strain Sensitivity of Coal Reinforced Smart Concrete by Piezoresistive Effect
}

\author{
Özkan Ayberk KOLATAR ${ }^{1}$ \\ Egemen TEOMETE ${ }^{2}$ \\ Serap KAHRAMAN ${ }^{3}$
}

\begin{abstract}
The structures are challenged by earthquakes, material degradations and other environmental factors. In order to protect the lives, assets, and for maintenance planning, structural health monitoring (SHM) is important. In SHM applications, strain gages are widely used which have low durability, low sensitivity while they have high cost. To monitor a structure, large number of strain gages have to be used that increases the cost. In this study, seven coal reinforced concrete mixtures with $0,0.35,0.5,0.8,1,1.5$ and 2 volume $\%$ of coal were designed; three cubic samples for each mixture were fabricated. Simultaneous strain and electrical resistance measurements of the samples during the compression test were conducted. A strong linear relationship between strain and electrical resistance change with a correlation coefficient of 0.99 was determined. The concrete mixture having $0.8 \%$ coal volume had the highest strain sensitivity of $\mathrm{K}=44$, which was 22 times the strain sensitivity of commercial metal strain gages while it had a linearity error of $\mathrm{LE}=6.9 \%$ that was low. This mixture with $0.8 \%$ coal volume is a candidate to be smart concrete which can sense its strain. As a contribution to the literature, a phenomenological model for the relationship between gage factor and coal volume percentage was explained in details. The multifunctional smart concrete will be used as a smart material, which can sense its strain in SHM applications while acting as a load bearing material.
\end{abstract}

Keywords: Smart concrete, strain, electrical resistance, smart materials, piezoresistivity.

Note:

- This paper was received on October 18, 2019 and accepted for publication by the Editorial Board on June 26, 2020.

- Discussions on this paper will be accepted by March 31, 2022.

- https://doi.org/10.18400/tekderg.634659

1 Dokuz Eylul University, Graduate School of Natural and Applied Sciences, Izmir, Turkey o.a.kolatar@gmail.com - https://orcid.org/0000-0002-5432-2879

2 Dokuz Eylul University, Civil Engineering Department, Izmir, Turkey - egemen.teomete@deu.edu.tr https://orcid.org/0000-0002-7330-7367

3 Dokuz Eylul University, Civil Engineering Department, Izmir, Turkey - serap.kahraman@deu.edu.tr https://orcid.org/0000-0002-7898-050X 


\section{INTRODUCTION}

Concrete is widely used for almost all civil engineering constructions. Concrete structures are challenged by earthquakes, material deteriorations and other environmental factors. Structural health monitoring is vital for the safety of life and assets while it is also important for asset management. Metal strain gages used for structural health monitoring have short life time, small sensitivity and can get point wise measurement. In order to monitor a structure, large number of strain gages are needed; increasing the number of channels in data acquisition system increases monitoring costs considerably [1]. Self-sensing smart concrete can be solution for these problems.

Different researchers worked on self-sensing cement composites reinforced with micro-nano fillers [1-4]. Carbon based materials were widely used due to their high electrical conductivity; among them carbon nanotubes were also widely tested within cement composites for strain sensing [5-9]. Carbon fiber, carbon nanofiber (CNF) and carbon black (CB) reinforced cement composites were used in cement composites for self-sensing [10-18]. Self-sensing cement composites were also tested with graphene and graphene nano-platelets [19-20].

Crack length sensitivity and strain gage factor of cement mortar composites reinforced with $13 \mathrm{~mm}$ carbon fibers were tested by Teomete [21]. Direct tensile test was applied to cement composites with $6 \mathrm{~mm}$ carbon fibers for strain sensing by Azhari et al. [22]. Effect of carbon fiber aspect ratio on self-sensing characteristics of cement pastes was investigated by Baeza et al. [23].

Studies on self-sensing smart concrete with large aggregates were very few. CNF filled concrete was investigated for strain sensing by Gao et al [24]. Wang et al [25] correlated the damage with electrical resistance of carbon fiber reinforced concrete under flexural loading. Relation between the damage and the resistivity of the carbon fiber reinforced concrete was investigated under cyclic loading by Chu and Chen [26].

Wen and Chung [27] compared the carbon fiber (15 $\mu \mathrm{m}$ diameter) reinforced cement paste and steel fiber reinforced ( $8 \mu \mathrm{m}$ diameter) cement paste for strain sensitivity. Teomete and Kocyigit [28] applied split tensile test to determine tensile strain sensitivity of steel fiber reinforced cement mortar. Dong et al. [29] tested reactive powder cement composite that had short-cut super-fine stainless wire and quartz sand for strain sensitivity under compression and flexure. Steel fibers and CNTs were used together in hybrid cement mortars under compression and direct tension test for strain sensing [30-31]. Steel fiber reinforced clay bricks under compressive load were tested for strain sensing [32].

Untreated coal waste increased the compressive strength by $5 \%$ and flexural strength by $6 \%$ when replaced $5 \%$ by weight of aggregate [33]. When cement was replaced by fly ash and coal gangue by $20 \%$, (fly ash / coal gangue ratio was $40 / 60$ in this $20 \%$ replacement), $4.5 \%$ increase in compressive strength was observed [34]. The tensile strength/cost ratio of concrete was optimized by coal waste considering the cost, the optimal coal waste percent was reported [35]. Splitting tensile, compressive and flexural strengths decreased by addition of ceramic and coal wastes [36]. Coal waste powder when used 5\% of binder increased compressive strength and toughness in bending at 28 days [37]. 
In literature, there is no study on strain sensitivity of coal reinforced cement composite (cement paste, mortar or concrete). In this study, strain sensitivity of low cost coal reinforced industrial concrete with $15 \mathrm{~mm}$ aggregate size was studied. Seven concrete mixtures with coal volume ratio of $0,0.35,0.5,0.8,1,1.5,2 \%$ were designed; three $75 \mathrm{~mm}$ cubes were cast and cured for each mixture; 21 cubes were prepared. Simultaneous strain and electrical resistance measurements were conducted during the compressions tests. For each mixture, strain sensitivity and linearity were determined as performance measures. There was strong linear relationship between strain and electrical resistance change of coal reinforced concrete.

\section{MATERIALS AND METHOD}

In this study, seven different concrete mixtures were designed. Reference mixture M0 had no coal while mixtures $\mathrm{K} 035, \mathrm{~K} 05, \mathrm{~K} 08, \mathrm{~K} 10, \mathrm{~K} 15, \mathrm{~K} 20$ had coal at $0.35,0.5,0.8,1,1.5$ and $2 \%$ by volume. In all mixes, cement CEM II B-M (L-W) $42.5 \mathrm{R}$, water/binder ratio of 0.37 ; silica fume/binder ratio of $10 \%$, super-plasticizer/binder ratio of $1 \%$ were utilized. The coal had a particle size of 0-10 mm, as seen in Fig. 1 . The density of coal was $1295 \mathrm{~kg} / \mathrm{m}^{3}$.

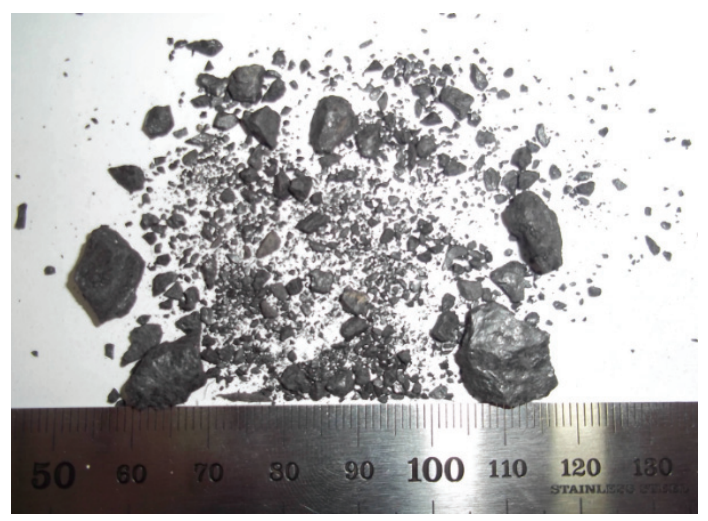

Figure 1 - The coal used in the study.

Modified polycarboxylates based polymer super plasticizer was used. Crushed lime stone fine and coarse aggregates of 0-5 $\mathrm{mm}$ and 5-15 $\mathrm{mm}$ were used, respectively. Silica fume that has spherical shape with average diameter of $250 \mu \mathrm{m}$ was used. The concrete mixtures were designed according to TS 802 "Design of Concrete Mixes" standard. The amount of materials in $1 \mathrm{~m}^{3}$ of concrete is presented in Table 1 .

Electrical resistance of cement composites was measured using either two or four probe measurement method. In two-probe method, sample cross section, distance between electrodes and contact resistance affects the measurements while in four-probe method, these do not affect the measurements [38, 39]. In this study, for electrical measurements of the smart concrete, different electrode pairs were used in four-probe method for current supply and voltage measurement. There was $35 \mathrm{~mm}$ between inner electrodes and $55 \mathrm{~mm}$ between outer electrodes. 
Table 1 - Amount of materials in $1 \mathrm{~m}^{3}$ of concrete $\left(\mathrm{kg} / \mathrm{m}^{3}\right)$.

\begin{tabular}{lccccccc}
\hline Materials & M0 & K035 & K05 & K08 & K10 & K15 & K20 \\
\hline Fiber \% in total volume: & 0 & 0.35 & 0.5 & 0.8 & 1 & 1.5 & 2 \\
Coal & 0 & 5 & 6 & 10 & 13 & 19 & 26 \\
Cement & 499 & 499 & 499 & 499 & 499 & 499 & 499 \\
Gravel 5-15mm & 547 & 544 & 542 & 539 & 537 & 531 & 526 \\
Sand 0-5 mm & 821 & 815 & 813 & 808 & 805 & 797 & 789 \\
Silica fume & 55 & 55 & 55 & 55 & 55 & 55 & 55 \\
Water & 205 & 205 & 205 & 205 & 205 & 205 & 205 \\
Super-plasticizer & 6 & 6 & 6 & 6 & 6 & 6 & 6 \\
\hline
\end{tabular}

A conductive wire or paint is applied on the sample in perimetral (external) electrode method while a conductive plate or mesh is inserted in the sample in embedded electrode method $[17,18,40]$. In this study, copper wire mesh with square hole of $5 \mathrm{~mm}$ and wire diameter of $0.6 \mathrm{~mm}$ was used as electrodes. A special cube mold with $75 \mathrm{~mm}$ size and electrode slots on either side were designed and manufactured for this study as seen in Fig. 2a. When mixture was cast in the mold, some portions of the electrodes stay outside the mold as in Fig. $2 \mathrm{~b}$. Three of $75 \mathrm{~mm}$ cubic samples for each 7 mixture were cast. The samples were taken out of the molds 24 hours after casting and cured for 28 days in $20^{\circ} \mathrm{C}$ water.

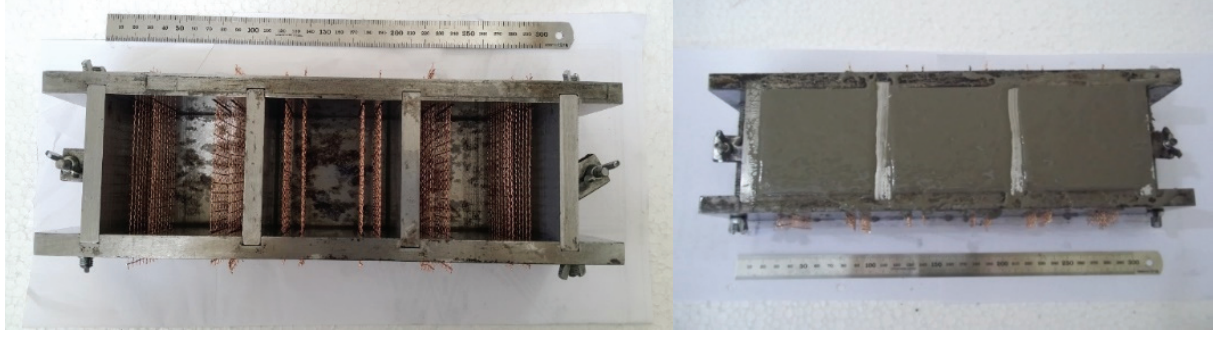

Figure 2 - a) Special mold and electrodes

b) After casting concrete

Before compression test, in order to eliminate the effects of polarization, $20 \mathrm{~V} \mathrm{DC}$ was applied on the samples for 15 minutes. Compression test was applied on the samples, with simultaneous measurement of strain and electrical resistance change. Strain was measured with strain gages. $300 \mathrm{kN}$ capacity electromechanical test machine was used with the loading rate of $0.5 \mathrm{~mm} / \mathrm{min}$. In order to insulate the samples, glass fiber epoxy plates were used as in Fig.3a. During compression test, $20 \mathrm{~V}$ DC was supplied using the outer two electrodes $\left(\mathrm{E}_{\mathrm{c}}\right)$, potential difference of the sample Vs was measured using the inner two electrodes $\left(E_{v}\right)$ as seen in Fig.3. Also, during the test, the potential difference $\left(V_{r}\right)$ of the reference resistance $(\mathrm{Rr}=1000 \mathrm{Ohms})$ and the current on the circuit $\mathrm{I}_{\mathrm{c}}$ were measured as presented in Fig. $3 \mathrm{~b}$. 
Force, strain, potential differences $\left(\mathrm{V}_{\mathrm{s}}, \mathrm{V}_{\mathrm{r}}\right)$, and current were recorded at a rate of $10 \mathrm{~Hz}(10$ sample/sec).

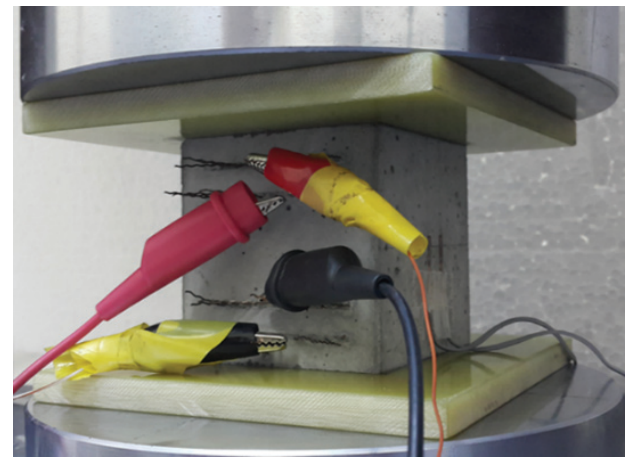

Figure 3 - a) The concrete sample at compression test

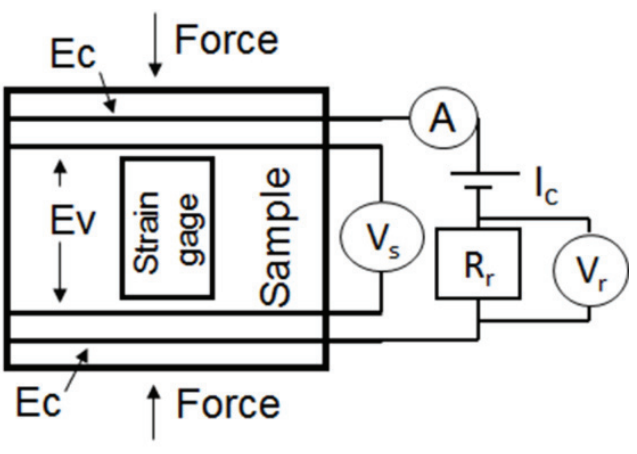

b) Test circuit

Measured circuit current $I_{c}$ and the electrical potential of the sample $V_{s}$ were used to determine the electrical resistance of the sample $\left(R_{s}\right)$ by Eq. 1. The percent change of electrical resistance of the sample $(\% \mathrm{R})$ was calculated by Eq. $2 . \mathrm{R}_{\mathrm{so}}$ is the electrical resistance of the sample without any applied load.

$$
\begin{aligned}
& R_{s}=\frac{V_{s}}{I_{c}} \\
& \% R=\left(\frac{R_{s}}{R_{s o}}-1\right) \times 100
\end{aligned}
$$

Strain sensing performance was assessed using gage factor (K) and linearity (LE). Gage factor $(\mathrm{K})$ is the change in electrical resistance per unit strain and determined by Equation 3 . Commercial metal foil strain gages have gage factors around 2 . The higher the gage factor the more sensitive to strain the sensor is. Linearity (LE) is the percent of maximum difference $\left(\Delta_{\max }\right)$ between the input-output curve ( $\% \mathrm{R}$ versus strain curve) and fitted linear regression line, to full-scale output $\left(\% \mathrm{R}_{\mathrm{fs}}\right)$ as in Equation 4 . As the linearity decreases, the error in strain measurement decreases.

$$
\begin{gathered}
K=\frac{\left(R_{s}-R_{s o}\right) / R_{s o}}{\Delta \varepsilon} \\
\% L E=\left(\frac{\Delta_{\max }}{\% R_{f s}}\right) \times 100
\end{gathered}
$$




\section{RESULTS AND DISCUSSIONS}

In this study, seven different concrete mixtures having different coal volume fractions were designed; three cube samples of $75 \mathrm{~mm}$ were tested with compression test for each mixture.

Electrical resistance - strain relationship was investigated. The stress- strain - electrical resistance change relationship for all mixtures are presented in Figs. 4-5. The compressive strain closed micro voids, leading to an increase in contacts of fiber-fiber and fiber-matrix, resulting in better electron and ion transfer; decreasing electrical resistance. Thus, piezoresistive effect is observed for all mixtures with or without coal.

The M0 mixture (without any coal) had an average gage factor of $\mathrm{K}=18.9$ and average linearity of $\mathrm{LE}=20.8 \%$ with a correlation coefficient of $\mathrm{R}^{2}=0.93$ as seen in Fig. 4 . The K035 mixture which had 0.35 volume \% coal was more sensitive to strain with respect to M0, with an average gage factor of 23.5, average linearity of $\mathrm{LE}=9.8 \%$ and a correlation coefficient of $\mathrm{R}^{2}=0.99$, presented in Fig.5a.

The mixture K05 with 0.5 volume \% of coal, had a higher gage factor (sensitivity) with respect to $\mathrm{K} 035$ and $\mathrm{M} 0$, with a gage factor of $\mathrm{K}=37$. It had an average linearity of $\mathrm{LE}=6.5 \%$, and correlation coefficient of $\mathrm{R}^{2}=0.99$, as in seen Fig. $5 \mathrm{~b}$. Increasing the coal amount to $0.8 \%$ volume fraction (for K08 mixture) further increased the gage factor to $\mathrm{K}=44$, with a low linearity of $\mathrm{LE}=6.9 \%$ and a correlation coefficient of $\mathrm{R}^{2}=0.99$ between strain and \% presented in Fig.5c. Further increase of volume percent to $1 \%$ coal led to a decrease of gage factor to $\mathrm{K}=37.7$ for mixture $\mathrm{K} 10$, increased linearity to $\mathrm{LE}=10.6 \%$ and a correlation coefficient of $\mathrm{R}^{2}=0.99$ (Fig. $5 \mathrm{~d}$ ). When the coal volume $\%$ was increased to $1.5 \%(\mathrm{~K} 15)$ and $2 \%(\mathrm{~K} 20)$, the gage factor was decreased to $\mathrm{K}=26$ and $\mathrm{K}=30$; the linearity increased to $\mathrm{LE}=14 \%$ and $\mathrm{LE}=9 \%$, with correlation coefficients of $\mathrm{R}^{2}=0.99$ and $\mathrm{R}^{2}=0.98$, respectively (Figs. 5e-f). For most mixtures with coal, the correlation coefficient between strain and \%R was $0.99 \%$ which testified strong linear relationship.

The variations of average gage factor and $\mathrm{LE} \%$ with coal volume percent was presented in Fig.6a-b, respectively. The error bars represent \pm 1 standard deviation from average. As seen in Fig.6a, the gage factor increased up to $0.8 \%$ volume ratio, than decreased with increasing volume ratio over $0.8 \%$. At low volume ratios (below $0.8 \%$ ), there was not enough fiber for new contact formation with strain which led to an increase of gage factor with coal volume $\%$. On the other hand, at higher volume ratios than $0.8 \%$, there are already some direct fiber contacts and development of new fiber contacts with strain did not affect the electrical resistance much, decreasing the gage factor $\mathrm{K}$. Thus, the optimal coal volume percentage was $0.8 \%$ for gage factor.

Fig. $6 \mathrm{~b}$ showed that the optimal volume percentage of 0.8 had one of the smallest linearity error. The mixture M08 with $0.8 \%$ volume ratio of coal, had the highest gage factor $\mathrm{K}=44$, which was 22 times the gage factor of commercial metal strain gages. It had the lowest linearity $\mathrm{LE} \%=6.9 \%$ which can be accepted for a multifunctional material. Thus, the M08 mixture was the most sensitive to strain with least error and a candidate to be smart concrete which can sense its strain. 


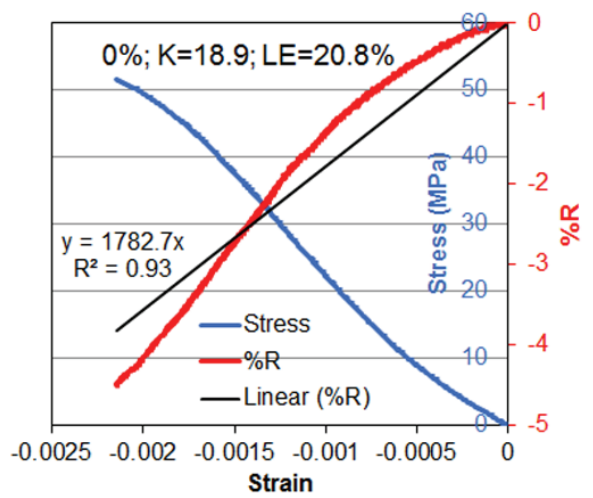

Figure 4 - Stress- strain- electrical resistance change $(\% R)$ relationship for concrete mixture $M 0(0 \% ; \mathrm{K}=18.9 ; \mathrm{LE}=20.8 \%)$

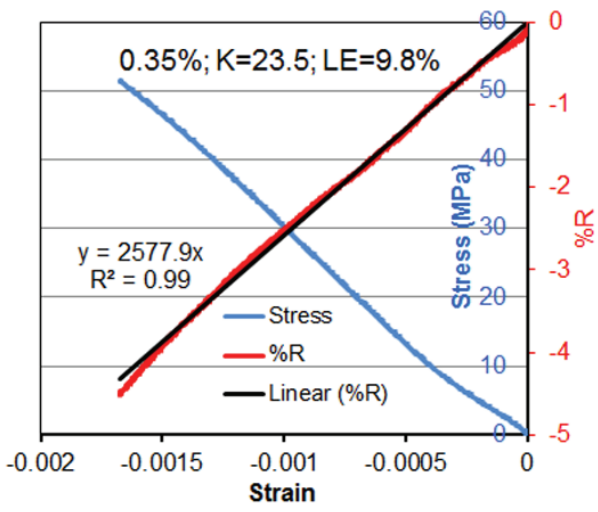

(a)

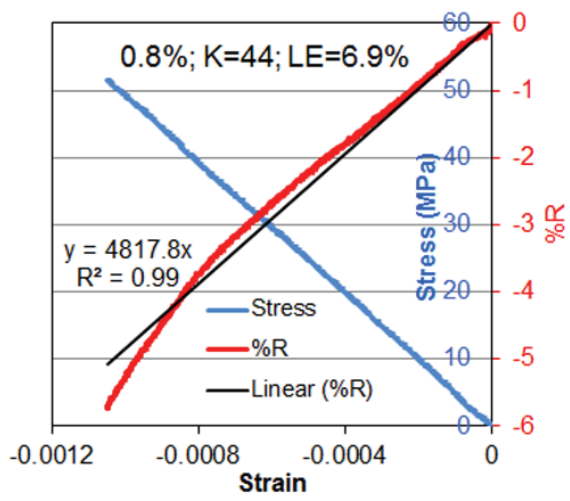

(c)

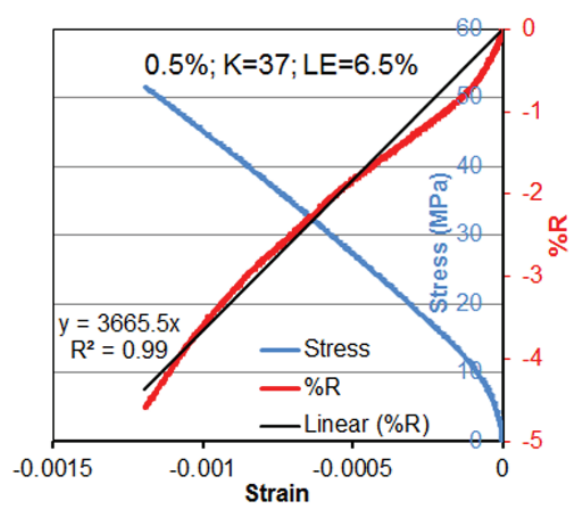

(b)

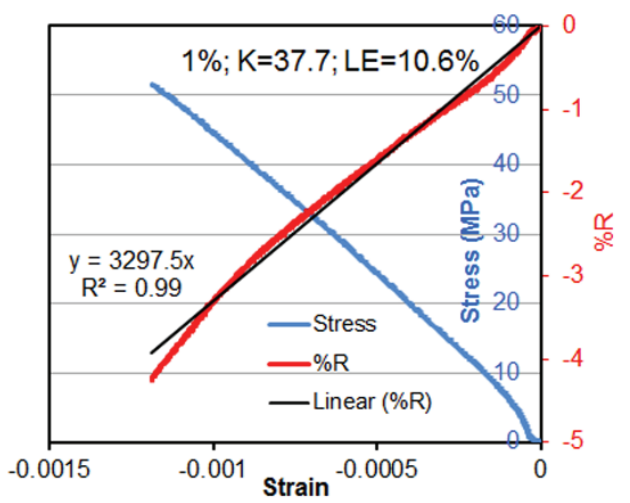

(d) 


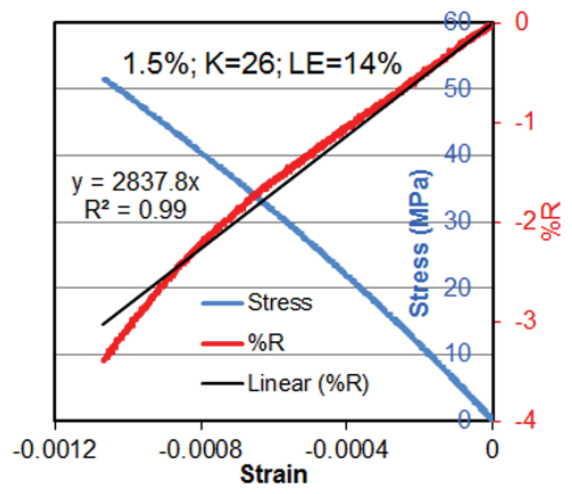

(e)

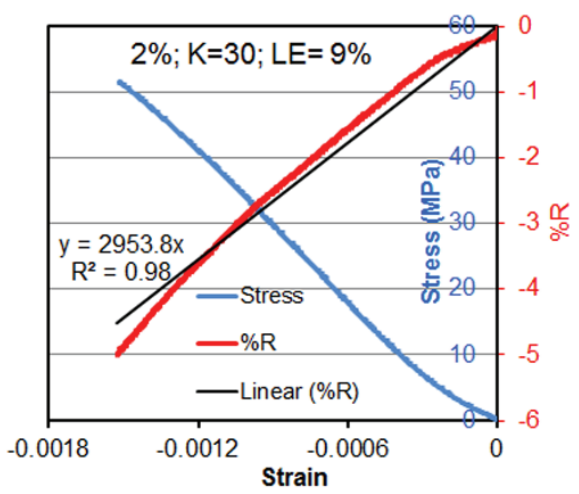

(f)

Figure 5 - Stress- strain- electrical resistance change $(\% R)$ relationship for concrete mixtures (a) K035; (b) K05; (c) K08; (d) K10; (e) K15; (f) K20.
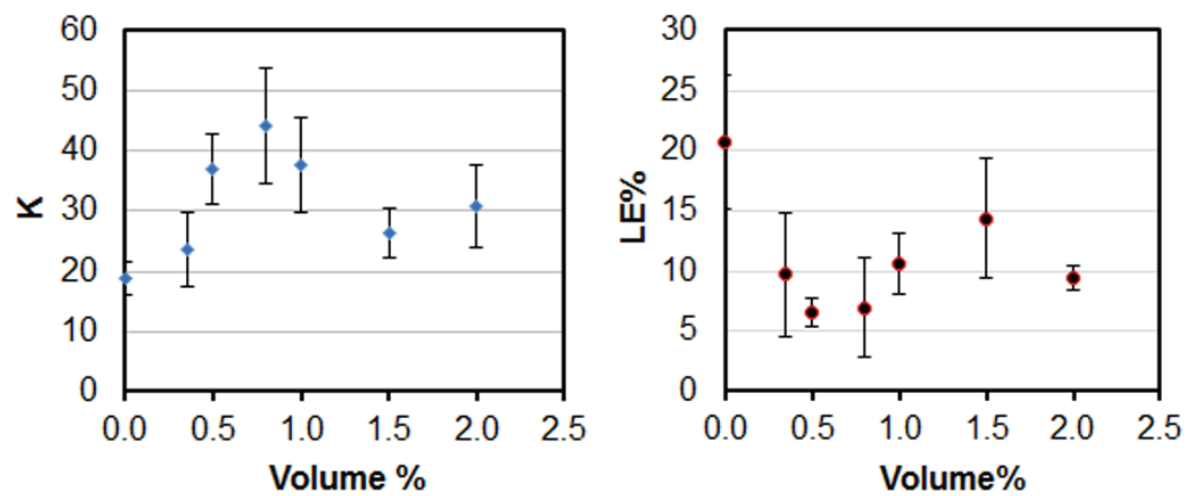

Figure 6 - Relationship between coal volume \% and a) Gage factor K b) Linearity LE\%

The phenomenological variation of gage factor with coal volume percentage was explained in details in Fig.7. The existing contacts were shown with brown coal particles (in Fig. 7e-f) while all new contacts occurred due to loading were shown with red coal particles. At coal volume percentage lower than $0.8 \%$, there were small number of coal particles, which did not contact each other before loading while there was only one partial contact after loading as seen in Fig.7a-b. As the coal volume increased to $0.8 \%$, there were more coal particles which did not contact before loading but developed some contacts after loading as seen in Fig. 7c-d. These new contacts decreased the electrical resistance considerably and maximized the gage factor as seen in Fig. 6a. As the coal volume increased beyond $0.8 \%$, some contacts already existed before loading shown with brown (in Fig.7e), and application of load only developed some more new contacts (shown in red in Fig.7f) which did not alter the resistivity much, resulting in a decrease in gage factor in Fig.6a. 

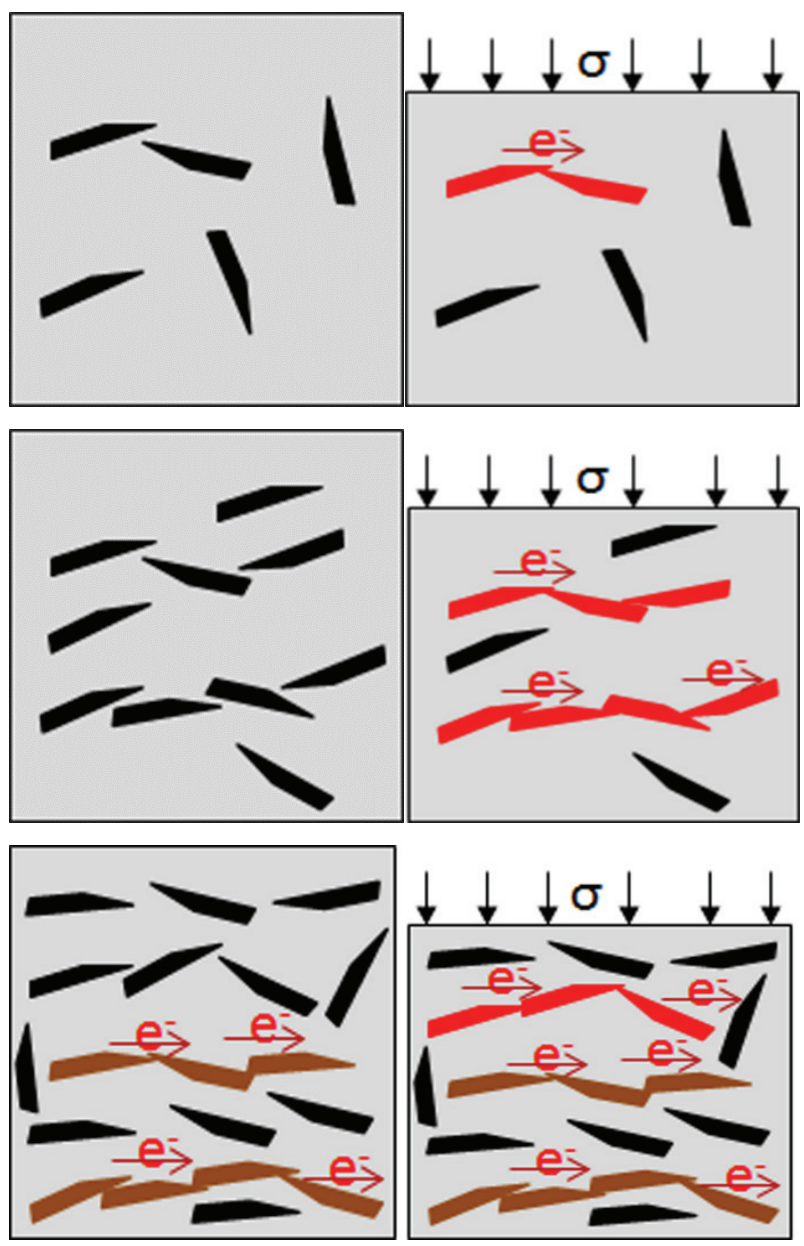

Figure 7 - Compression test of coal reinforced concrete at volume \% of $a$-b) Lower than $0.8 \%(-d)$ At $0.8 \%$ and $e-f)$ Higher than $0.8 \%$. Existing contacts are brown and new contacts are red.

\section{CONCLUSIONS}

In this study, strain sensitivity of coal reinforced concrete was determined for seven different volume percentages of coal. Three $75 \mathrm{~mm}$ cube samples were cast and tested with compression test for each mixture. Strain and electrical resistance measurements were conducted simultaneously. The results presented in this work are only valid for the sample size of $75 \mathrm{~mm}$ due to size effect phenomenon of concrete and only under monotonic uniaxial compression loading. Other sample sizes and loading conditions (tensile, shear, bending, cyclic etc.) can be studied as future study. The results of this study are presented below: 
1. The electrical resistance of coal reinforced concrete decreased with compressive strain due to closing of micro voids which led to an increase in fiber - fiber and fiber-matrix contact. Piezoresistive effect was observed.

2. All the coal reinforced concrete mixtures had a strong linear relationship between strain and $\% \mathrm{R}$ with a correlation coefficient of $\mathrm{R}^{2}=0.99$.

3. At coal volume percentages lower than 0.8 as there was a small amount of fibers, resistance change was less due to strain because of low amount of new fiber contacts by strain, which ended up with low gage factors. As the coal volume percentage increased, strain could develop more fiber contacts which changed electrical resistance more and gage factor increased. At coal volume percentages higher than 0.8 , there were already fiber contacts existed prior to loading and new contacts due to strain did not affect the electrical resistance much, gage factor decreased. The optimal coal volume $\%$ was 0.8 at which the change in electrical resistance and gage factor were maximum.

4. The M08 mixture with $0.8 \%$ coal had the lowest linearity error of $\mathrm{LE}=6.9 \%$ which was acceptable for a multifunctional smart concrete. It had the highest gage factor of $K=44$, which was 22 times the gage factor of commercial metal strain gages. Thus, M08 mixture, with highest gage factor and lowest linearity, is a candidate to be multifunctional self-sensing smart concrete.

Smart concrete can be used in important structures (hospitals, nuclear power plants etc.) and only at critical structural elements (Columns of $1^{\text {st }}$ floor etc.) to monitor the structural health. Wireless data transfer and real time monitoring can be applied while discrete measurements can also be obtained after a major event (seismic load, impact) for damage assessment. Commercial metal strain gages can get point wise measurements while smart concrete can monitor entire structure. The coal dust used had a lower price than steel fibers, carbon fibers, carbon nanotubes and graphite, which makes implementation of smart concrete economical for the industry.

\section{Acknowledgements}

This work was supported by The Scientific and Technological Research Council of Turkey (TUBITAK) through project "Smart Concrete Production", Grant no: 213M452. The authors would like to thank to Batıbeton Batıçim West Anatolia Cement Industry Inc. for supplying cement and aggregate; Sika Construction Chemicals Co. for supplying super plasticizer; BASF Chemical Co. for supplying silica fume, Turkish Coal Institution for supplying coal.

\section{References}

[1] Chung, D.D.L., Review functional properties of cement -matrix composites. Journal of Material Science, 36, 1315-1324, 2001.

[2] Chung, D.D.L., Piezoresistive cement-based materials for strain sensing. Journal of Intelligent Material Systems and Structures, 13(9), 599-609, 2002.

[3] Chung, D.D.L., Carbon materials for structural self-sensing, electromagnetic shielding and thermal interfacing. Carbon, 50(9), 3342-3353, 2012. 
[4] Lu, S.N., Xie, N., Feng, L.C., Zhong, J., Applications of nanostructured carbon materials in constructions: the state of the art. Journal of Nanomaterials, ID: 807416, 2015.

[5] Han, B., Yu, X., Kwon, E., A self-sensing carbon nanotube/cement composite for traffic monitoring. Nanotechnology, 20(44), 1-5, 2009.

[6] Han, B., Zhang, K., Burnham, T., Kwon, E., Yu, X., Integration and road tests of a selfsensing CNT concrete pavement system for traffic detection. Smart Materials and Structures, 22(1), ID: 015020, 2013.

[7] Al-Dahawi, A., Sarwary, M. H., Öztürk, O., Yıldırım, G., Akın, A., Şahmaran, M., Lachemi, M., Electrical percolation threshold of cementitious composites possessing self-sensing functionality incorporating different carbon-based materials. Smart Materials and Structures, 25(10), ID: 105005, 2016.

[8] Jianlin, L., Kwok, L.C., Qiuyi, L., Shunjian, C., Lu, L., Dongshuai, H., Chunwei, Z., Piezoresistive properties of cement composites reinforced by functionalized carbon nanotubes using photo-assisted fenton. Smart Materials and Structures, 26(3), ID: $035025,2017$.

[9] Luo, J., Zhang, C., Duan, Z., Wang, B., Li, Q., Chung, K.L., Zhang, J., Chen, S., Influences of multi-walled carbon nanotube (MCNT) fraction, moisture, stress/strain level on the electrical properties of MCNT cement-based composites. Sensors and Actuators A: Physical, 280, 413-421, 2018.

[10] Meehan, D.G., Wang, S., Chung, D.D.L., Electrical-resistance-based sensing of impact damage in carbon fiber reinforced cement-based materials, Journal of Intelligent Material Systems and Structures, 21(1), 83-105, 2010.

[11] Han, B., Wang, Y., Dong, S., Zhang, L., Ding, S., Yu, X., Ou, J., Smart concretes and structures: A review. Journal of Intelligent Material Systems and Structures, 26(11), 1303-1345, 2015.

[12] Goldfeld, Y., Rabinovitch, O., Fishbain, B., Quadflieg, T., Gries, T., Sensory carbon fiber based textile-reinforced concrete for smart structures. Journal of Intelligent Material Systems and Structures, 27(4), 469-489, 2016.

[13] Han, B., Wang, Y., Ding, S., Yu, X., Zhang, L., Li, Z., Ou, J., Self-sensing cementitious composites incorporated with botryoid hybrid nano-carbon materials for smart infrastructures. Journal of Intelligent Material Systems and Structures. 28(6), 699-727, 2017.

[14] Wang, H., Gao, X., Liu, J., Coupling effect of salt freeze-thaw cycles and cyclic loading on performance degradation of carbon nanofiber mortar. Cold Regions Science and Technology, 154, 95-102, 2018.

[15] Wang, Y., Wang, Y., Wan, B., Han, B., Cai, G., Chang, R., Strain and damage selfsensing of basalt fiber reinforced polymer laminates fabricated with carbon nanofibers/epoxy composites under tension. Composites Part A, 113, 40-52, 2018b. 
[16] Wang, Y., Wang, Y., Wan, B., Han, B., Cai, G., Li, Z., Properties and mechanisms of self-sensing carbon nanofibers/epoxy composites for structural health monitoring. Composite Structures, 200, 669-678, 2018.

[17] Li, H., Xiao, H., Ou, J., Effect of compressive strain on electrical resistivity of carbon black-filled cement -based composites. Cement and Concrete Composites, 28, 824$828,2006$.

[18] Li, H., Xiao, H., Ou, J., Electrical property of cement-based composites filled with carbon black under long-term wet and loading condition. Composites Science and Technology, 68, 2114-2119, 2008.

[19] Ozbulut, O. E., Jiang, Z., Harris, D. K., Exploring scalable fabrication of selfsensing cementitious composites with graphene nanoplatelets. Smart Materials and Structures, 27(11), ID: 115029, 2018.

[20] Rehman, S. K., Ibrahim, Z., Jameel, M., Memon, S. A., Javed, M. F., Aslam, M., Mehmood, K., Nazar, S., Assessment of rheological and piezoresistive properties of graphene based cement composites. International Journal of Concrete Structures and Materials, 12(1), UNSP 64, 2018.

[21] Teomete, E., Measurement of crack length sensitivity and strain gage factor of carbon fiber reinforced cement matrix composites. Measurement, 74, 21-30, 2015.

[22] Azhari, F., Banthia, N., Carbon fiber-reinforced cementitious composites for tensile strain sensing. ACI Materials Journal, 114(1), 129-136, 2017.

[23] Baeza, F. J., Galao, O., Zornoza, E., Garcés, P., Effect of aspect ratio on strain sensing capacity of carbon fiber reinforced cement composites. Materials \& Design, 51, 10851094, 2013.

[24] Gao, D., Sturm, M., Mo, Y. L., Electrical resistance of carbon-nanofiber concrete, Smart Materials and Structures, 18(9), ID:095039, 2009.

[25] Wang, W., Wu, S., Dai, H., Fatigue behavior and life prediction of carbon fiber reinforced concrete under cyclic flexural loading. Materials Science and Engineering, 434(1-2), 347-351, 2006.

[26] Chu, H. Y., Chen, J. K., The experimental study on the correlation of resistivity and damage for conductive concrete. Cement and Concrete Composites, 67, 12-19, 2016.

[27] Wen, S., Chung, D. D. L., A comparative study of steel- and carbon-fibre cement as piezoresistive strain sensors. Advances in Cement Research, 15(3), 119-128, 2003.

[28] Teomete, E., Kocyigit, O. I., Tensile strain sensitivity of steel fiber reinforced cement matrix composites tested by split tensile test. Construction and Building Materials, 47, 962-968, 2013.

[29] Dong, S., Han, B., Ou, J., Li, Z., Han, L., Yu, X., Electrically conductive behaviors and mechanisms of short-cut super-fine stainless wire reinforced reactive powder concrete. Cement \& Concrete Composites, 72, 48-65, 2016. 
[30] Lee, S. H., Kim, S., Yoo, D. Y., Hybrid effects of steel fiber and carbon nanotube on self-sensing capability of ultra-high-performance concrete. Construction and Building Materials. 185, $530-544,2018$.

[31] Yoo, D. Y., Kim, S., Lee, S. H., Self-sensing capability of ultra-high-performance concrete containing steel fibers and carbon nanotubes under tension. Sensors and Actuators A-Physical, 276, 125-136, 2018.

[32] D'Alessandro, A., Meoni, A., Ubertini, F., Stainless steel microfibers for strain-sensing smart clay bricks. Journal of Sensors, ID:7431823, 2018.

[33] Karimaei, M., Dabbaghi, F., Sadeghi-Nik, A., Dehestani, M., Mechanical performance of green concrete produced with untreated coal waste aggregates. Construction and Building Materials, 233, Article Number: UNSP 117264, 2020.

[34] Wang, Y., Tan, Y., Wang, Y., Liu, C., Mechanical properties and chloride permeability of green concrete mixed with fly ash and coal gangue. Construction and Building Materials, 233, Article Number: 117166, 2020.

[35] Khataei, B., Nasrollahi, M., Optimizing the tensile strength of concrete containing coal waste considering the cost. Sn Applied Sciences, 2 (1) Article Number: 103, 2020.

[36] Shamsaei, M., Khafajeh, R., Aghayan, I., Laboratory evaluation of the mechanical properties of roller compacted concrete pavement containing ceramic and coal waste powders. Clean Technologies and Environmental Policy, 21(3), 707-716, 2019.

[37] Modarresa, A., Hesamia, S., Soltaninejada, M., Madanib, H., Application of coal waste in sustainable roller compacted concrete pavement-environmental and technical assessment. International Journal of Pavement Engineering, 19(8), 748-761, 2018.

[38] Chiarello, M., Zinno, R., Electrical conductivity of self-monitoring CFRC. Cement and Concrete Composites, 27, 463-469, 2005.

[39] Han, B., Guan, X., Ou, J., Electrode design, measuring method and data acquisition system of carbon fiber cement paste piezoresistive sensors. Sensors and Actuators A, 135, 360-369, 2007.

[40] Chen, B., Liu, J., Damage in carbon fiber -reinforced concrete, monitored by both electrical resistance measurement and acoustic emission analysis. Construction and Building Materials, 22, 2196-2201, 2008. 
